\title{
Characterization of Thaumatin-like Gene Family and Identification of Pectobacterium carotovorum subsp. carotovorum Inducible Genes in Brassica oleracea
}

\author{
Nasar Uddin Ahmed ${ }^{1}$, Jong-In Park ${ }^{1}$, Hee-Jeong Jung ${ }^{1}$, Mi-Young Chung ${ }^{2}$, Yong-Gu $\mathrm{Cho}^{3}$, and Ill-Sup Nou ${ }^{1}$ * \\ ${ }^{1}$ Department of Horticulture, Sunchon National University, 413 Jungangno, Suncheon, Jeonnam 540-742, Republic of Korea \\ ${ }^{2}$ Department of Agricultural Education, Sunchon National University, 413 Jungangno, Suncheon, Jeonnam 540-742, Republic of Korea \\ ${ }^{3}$ Department of Crop Science, Chungbuk National University, 410 Seongbongro, Heungdokgu, Cheongju 361-763, Republic of Korea
}

\begin{abstract}
Cabbage (Brassica oleracea) is a very important vegetable worldwide and biotic stress is a crucial issue for this crop. Enhancement of resistance by exploiting stress resistance-related genes offers the most efficient approach to address this issue. Among the stress resistance-related genes, thaumatin-like proteins (TLPs) play a vital role in enhancement of resistance against stresses. In this study, we identified 12 TLPs from B. oleracea genomic DNA sequencing database, analyzed their sequences and compared with other published pathogenesis-related TLPs, and found a high degree of homology with them. In addition, these genes showed an organ-specific expression, three of which expressed differentially after Pectobacterium carotovorum subsp. carotovorum infection in cabbage plants. Data obtained in this study suggest the probable involvement of TLPs in resistance against soft rot disease of Brassica.
\end{abstract}

Keywords Brassica, Gene expression, Pectobacterium carotovorum subsp. carotovorum, Thaumatin-like protein

\section{INTRODUCTION}

Brassica crops are sternly challenged by various fungal, bacterial, and viral diseases and insect pests which led to enormous losses of yield. Brassica vegetables are highly susceptible to bacterial soft rot disease, which is caused by a gram-negative bacterium, Pectobacterium carotovorum subsp. carotovorum $(P c c)$. Bacterial soft rot is the most severe and destructive disease, which causes serious damage and economic losses across the members of Brassica. Control of this pathogen is difficult due to its ability to infect a wide range of hosts and to survive on plant debris. Effective chemical controls are not available so far. Cultural practices, including raised planting beds, reduced plant density, and delayed planting dates can reduce disease frequency and progression, but may reduce agricultural efficiency (Fritz and Honma 1987). Genetic tolerance or resistance may represent an ideal alternative approach. But the traditional recurrent selection procedure is labor intensive and time-consuming. Moreover, due to lack of natural resistant genes against soft rot disease, the proceeding of routine raising disease-resistance breeding is restricted $(\mathrm{Li}$ 1995). Therefore, genetic engineering of soft rot disease tolerance in Brassica is of significant interest to agricultural biotechnology.

Plants respond to biotic stress factors by producing various defense-related proteins such as pathogenesisrelated (PR) proteins, hydroxyproline-rich glycoproteins (HRGPs), and several key enzymes involved in the synthesis of phenylpropanoids, phytoalexins and lignins (Collinge and Slusarenko 1987; Bowles 1990; Dixon and Lamb 1990). One promising strategy to develop resistance against biotic stresses is based on the exploitation of PRs and other stress responsive genes in transgenic plants. Accumulation of PRs extends into non-inoculated plant parts that, upon challenge, exhibit acquired resistance (Van Loon and Van Kammen 1970; Ryals et al. 1996). PR proteins are classified into 17 families based on sequence similarity and biochemical

Received May 25, 2013; Revised Jun 17, 2013; Accepted Jun 18, 2013; Published June 30, 2013

*Corresponding author Ill-Sup Nou, nis@sunchon.ac.kr, Tel: +82-61-750-3249, Fax: +82-61-750-3208 
functions (Van loon et al. 2006). An important common feature of most PR proteins is their antifungal effect. In addition, some PR proteins exhibit antibacterial, insecticidal, nematicidal, and anti-viral action (Van Loon and Van Strien 1999; Selitrennikoff 2001; Van Loon 2001).

Owing to the sequence homology between PR-5 proteins and thaumatin, an intensely sweet-tasting protein isolated from the fruit of the West African rainforest shrub Thaumatococcus daniellii (Bennett) Benth (Iyengar et al. 1979), members of this family of proteins are referred to as thaumatin-like proteins (TLPs). This family also includes the closely related proteins permatin, osmotin and zeamatin. TLPs play a variety of roles including development of seed, fruit and flower tissues, and specific TLPs have been shown to protect plants against osmotic stress, pathogen attack and the deleterious effects of freezing (Velazhahan et al. 1999; An lovar and Dermastia 2003). The expression of some TLPs is induced by biotic and abiotic factors, such as microbial infection, osmotic stress, abscisic acid (ABA), ethylene, salicylic acid (SA), methyl jasmonate (MJ) and elicitors (Kitajima and Sato 1999; Velazhahan et al. 1999). Purified TLPs from several plant species have in vitro anti-fungal activity. Several antifungal modes of action have been described such as membrane permeabilization (Vigers et al. 1991), $\beta$-glucan binding and degradation (Sakamoto et al. 2006), inhibition of enzymes such as xylanases (Fierens et al. 2007), a-amylase, or trypsin (Schimoler-O'Rourke et al. 2001), as well as an apoptosisinducing mechanism reported in yeast (Narasimhan et al. 2005). A PR5 protein from Arabidopsis thaliana ATLP3, showed considerable antifungal activity against pathogenic fungi such as Verticillium alboatrum, $V$. dahliae and Fusarium oxysporum (Hu and Ready 1997). PR5 proteins from mutant barley grain inhibited growth of Trichoderma viride and Candida albicans (Hejgaard et al. 1991). In addition to inhibiting hyphal growth and spore germination, some TLPs greatly increase the permeability of fungal and oomycete plasma membranes (Yun et al. 1997; Kitajima and Sato 1999). Overexpression of TLPs appears to enhance resistance to fungal disease (Liu et al. 1994; Zhu et al. 1996; Chen et al. 1999). Moreover, TLPs in various plant-derived foods (Hoffmann-Sommergruber 2002) and conifer pollen (Midoro-Horiuti et al. 2000; Cortegano et al.
2004) are allergens.

In our previous study, we characterized 20 thaumatinlike genes of $B$. rapa and found four genes to respond after P. carotovorum subsp. carotovorum infection in Chinese cabbage (Ahmed et al. 2013). In relation to the previous study, we identified 12 thaumatin-like genes of $B$. oleracea from Brassica oleracea Genome Database (Bolbase) (http:// 119.97.203.210/bolbase/index.html). We then analyzed the sequences and studied their homology with pathogenesisrelated thaumatin-like proteins of other species. In addition, expression of these genes was analyzed in different organs and after infection with $P$. carotovorum subsp. carotovorum in cabbage plants. We also discussed their association with biotic stress resistance in Brassica.

\section{MATERIALS AND METHODS}

\section{Plant materials}

Cabbage (Brassica oleracea 'ASC621') plants were grown at the Department of Horticulture, Sunchon National University, Korea. Fresh roots, stems, leaves and flower buds of the Chinese cabbage were harvested, immediately frozen in liquid nitrogen, and then stored at $-80^{\circ} \mathrm{C}$ until subsequent analysis in an organ-specific expression study.

\section{Stress treatments}

Chinese cabbage (B. oleracea 'ASC621') plants were grown for 6 weeks under culture room conditions with $16 \mathrm{~h}$ light and $8 \mathrm{~h}$ dark maintaining $25^{\circ} \mathrm{C}$ temperature prior to treatment. The $P$. carotovorum subsp. carotovorum stock (10 $\mu 1$ ) was cultured in $25 \mathrm{ml}$ of liquid YEP medium until $\mathrm{OD}_{600}$ reading is 1.4 or $1,170, \mathrm{cfu} \mathrm{ml}^{-1}$ and then diluted it to $\mathrm{OD}_{600}$ $=1.19$ or $1 \times 10^{6} \mathrm{CFU} \mathrm{ml}^{-1}$ by adding double- distilled water. For pathogen inoculation, $10 \mu 1$ of $P$. carotovorum subsp. carotovorum culture solution $\left(1 \times 10^{6} \mathrm{cfu} \mathrm{ml}^{-1}\right)$ was added to the freshly needle-wounded site (at the lower $1 / 3$ position) of the midrib of the upper third leaves, and incubated at $25^{\circ} \mathrm{C}$ covering with polyvinyl bags to maintain $80-90 \%$ humidity. All inoculations were performed three times, and the infection was confirmed by observing disease lesion in the leaves of Chinese cabbage plants. About one-third part from the top of the infected leaves were harvested for RNA 
extraction at $0,6,12,24,48$ and $72 \mathrm{~h}$ after inoculation, frozen in liquid nitrogen, and stored at $-80^{\circ} \mathrm{C}$.

\section{RNA extraction}

Total RNA of previously frozen roots, stems, leaves, flower buds and stress treated samples with Rneasy mini kit (Qiagen, USA) was extracted and treated with RNase-free DNase (Promega, USA) to remove genomic DNA contaminants. The cDNA was subsequently synthesized using a Superscript ${ }^{\circledR}$ III First-Strand synthesis kit (Invitrogen, USA) according to the manufacturer's instructions.

\section{Sequence analysis}

We collected 12 thaumatin-like proteins (BoTLP1 to 12) from Brassica oleracea Genome Database (Bolbase) (http: //119.97.203.210/bolbase/index.html) by blast searching of each 17 B. oleracea thaumatin-like protein ESTs (Table 1) collected from cabbage genomic project database (http://210.219.43.182:8080/brdb/search.jsp?species=bol \&classes $=$ all\&keyword $=$ BOLS24099\&length $=0$ \&identit $\mathrm{y}=0 \&$ block $=$ all\#). The primary structure of genes was analyzed using protParam (http://expasy.org/tools/protparam. html) and Augustus (http://augustus.gobics.de/submission). An alignment search was conducted using NCBI BLAST (http://www.ncbi.nlm.nih.gov/BLAST/) and the program
BLASTp, with the "nr" database. Typical domains were analyzed using the EMBL web tool (http://smart.embl.de/ smart/set_mode.cgi?GENOMIC $=1$ ). Multiple protein sequences were aligned using PIR (http://pir.georgetown.edu/pirwww/ search/multialn.shtml), and a phylogenetic tree was constructed according to the neighbor-joining method using the MEGA4.1 software (http://www.megasoftware.net) (Saitou and Nei 1987; Tamura et al. 2007).

\section{Expression analysis}

RT-PCR was conducted using an AMV one step RTPCR kit (Takara, Japan). Specific primers for all the genes were used for RT-PCR, and actin primers of Brassica rapa (FJ969844) were used as control (Table 1). PCR was performed using $50 \mathrm{ng}$ of cDNA from the roots, leaves, stems and flower buds as templates in master mixes composed of $20 \mathrm{pmol}$ of each primer, $150 \mu \mathrm{M}$ of each dNTP, 1.2 U of Taq polymerase, 1x Taq polymerase buffer, and double-distilled $\mathrm{H}_{2} \mathrm{O}$ diluted to a total volume of $20 \mu \mathrm{l}$ in $0.5 \mathrm{ml}$ PCR tubes. The samples were then subjected to the following conditions: pre-denaturing at $94^{\circ} \mathrm{C}$ for $5 \mathrm{~min}$, followed by 30 cycles of denaturation at $94^{\circ} \mathrm{C}$ for $30 \mathrm{~s}$, annealing at $58^{\circ} \mathrm{C}$ for $30 \mathrm{~s}$ and extension at $72^{\circ} \mathrm{C}$ for $1 \mathrm{~min}$, with a final extension for $5 \mathrm{~min}$ at $72^{\circ} \mathrm{C}$. Real-time quantitative PCR was performed using $1 \mu 1$ of cDNA in a

Table 1. Primer information of 12 thaumatin-like genes of B. oleracea for RT and Real time PCR.

\begin{tabular}{cccc}
\hline \hline \multirow{2}{*}{ Gene name } & Acc. No. of ESTs & \multicolumn{2}{c}{ Primer sequence } \\
\cline { 3 - 4 } BoTLP1 & BOLC06439 & CAGAAATCAACAAGCTACCC & GATCCGTCTTGTAACATCGT \\
BoTLP2 & BOLC11620 & TTTTCACCATCCAGAATAGC & GTCGAAGTTACAGCCTGTTC \\
BoTLP3 & BOLC12781 & TCTACCGTTTTCAAGAGAGC & CCGTACGGATTCTGAGTTAG \\
BoTLP4 & BOLC13543 & CTACTCTCGCAGAGATCACC & GAGTTAAAGGCAGAACATGC \\
BoTLP5 & BOLC14356 & CCCTGAAAGAAGAATGAGAA & ACAAGACGAGCACCTACACT \\
BoTLP6 & BOLC17729 & ACGACTTACTCGATGACGTT & ATCTTCCGTACATAGCAAGC \\
BoTLP7 & BOLC20473 & CCGCAAAAGCTCTTTATTAC & TATAGCTACGCATACGACGA \\
BoTLP8 & BOLC20492 & ATCCAGATGAGAATCACGAC & ACAAGTCTCCGGTTTATTGA \\
BoTLP9 & BOLC23111 & GTAGAGACGGGAACAAAACA & AAAGTTGCAGTGAAAAGCTC \\
BoTLP10 & BOLC23113 & ACGGGAGGATTCTTAATTGT & CAACGCAGCATTAGATAACA \\
BoTLP11 & BOLC23820 & CGTCCGGATTAATACTTGAG & AGTTGTACACCGTTGTCTCC \\
BoTLP12 & BOLS14849 & AGCAAAATCCATATCACAGG & GACTGTCCCACATCAAGTTT \\
Br-Actin & FJ969844 & CAACCAATCGTCTGTGACAA & ATGTCTTGGCCTACCAACAA \\
\hline
\end{tabular}


$25 \mu 1$ reaction volume employing iTaq ${ }^{\mathrm{TM}} \mathrm{SYBR}^{\circledR}$ Green Super-mix with ROX (California, USA). The specific primers used for real-time PCR are listed in Table 1. The conditions for real-time PCR were as follows: $10 \mathrm{~min}$ at $95^{\circ} \mathrm{C}$, followed by 40 cycles at $94^{\circ} \mathrm{C}$ for $30 \mathrm{~s}, 58^{\circ} \mathrm{C}$ for 30 $\mathrm{s}$, and $72^{\circ} \mathrm{C}$ for $45 \mathrm{~s}$. The fluorescence was measured following the last step of each cycle, and three replications were used for each sample. Amplification, detection, and data analysis were conducted using a Rotor-Gene 6000 real-time rotary analyzer (Corbett Life Science, Australia).

\section{RESULTS AND DISCUSSION}

\section{Identification and sequence analysis}

In this study, 12 thaumatin-like proteins, designated $B$. oleracea Thaumatin-like Protein (BoTLP) were identified and their sequences were analyzed and presented in the Table 2. The size of the 12 BrTLPs varies from 133 to 428 amino acids ( 14.66 to $45.33 \mathrm{kDa})$, and the predicted isoelectric points vary from 4.25 to 9.07 . Analysis of the protein domain organization showed that all these proteins contained the characteristic thaumatin (THN) domain in the conserved region located mostly from 1 to 190 amino acid positions of the protein sequences which covers almost 80 to $90 \%$ of the entire mature TLPs. Genomic DNA sequences pertaining structural information of all 12 genes were collected from Brassica oleracea Genome Database (Bolbase) (http://119.97.203.210/bolbase/index. $\mathrm{html}$ ). Most typical TLPs described to date have a molecular weight ranging from 20 to $26 \mathrm{kDa}$, and generally possess 16 conserved cysteine residues that form eight disulfide bonds (Ghosh and Chakrabarti 2008). Several TLP structures have been solved so far, revealing a strongly conserved 3D organization with a characteristic acidic cleft domain that comprises the five highly conserved amino acids REDDD that are dispersed in the primary sequence (Koiwa et al. 1999). Despite good conservation of these amino acids in primary sequences, they do not organize into an acidic cleft at the 3D level (Vandermarliere et al. 2010). The BoTLPs also contained 16 cysteine residues, REDDD and FF hydrophobic motif conserved in an identical position with other published TLPs and sweet tasting thaumatin protein (Fig. 2A and B). Alongside, it has become evident that several families of cysteine-rich basic antimicrobial polypeptides play an important role in protecting plants against invading phytopathogens (Garcia-Olmedo et al. 1998). These sequence data revealed that the identified

Table 2. Overall analysis of thaumatin-like genes collected from the Brassica oleracea database. ${ }^{\mathrm{z}}$

\begin{tabular}{|c|c|c|c|c|c|c|c|}
\hline \multirow[b]{2}{*}{ Name of genes } & \multirow{2}{*}{$\begin{array}{l}\text { Accession } \\
\text { Number }\end{array}$} & \multirow[b]{2}{*}{ ORF (bp) } & \multirow{2}{*}{$\begin{array}{c}\text { Chromosome } \\
\text { number }\end{array}$} & \multicolumn{4}{|c|}{ Protein } \\
\hline & & & & Length (aa) & $\begin{array}{l}\text { THN domain } \\
\text { Start and end }\end{array}$ & $\begin{array}{l}\text { Mol.Wt. } \\
\text { (KD) }\end{array}$ & $\mathrm{pI}$ \\
\hline BoTLP1 & Bol016062 & 1041 & $\mathrm{C} 03$ & 346 & 1 to 184 & 35.58 & 4.25 \\
\hline BoTLP2 & Bol044835 & 738 & $\mathrm{C} 08$ & 245 & 1 to 185 & 25.32 & 5.05 \\
\hline BoTLP3 & Bol022411 & 1098 & $\mathrm{C} 07$ & 365 & 1 to 189 & 38.56 & 5.31 \\
\hline BoTLP4 & Bol026250 & 738 & $\mathrm{C} 06$ & 245 & 1 to 181 & 26.15 & 9.07 \\
\hline BoTLP5 & Bol000789 & 825 & Scaffold & 274 & 1 to 185 & 29.22 & 8.91 \\
\hline BoTLP6 & Bol026131 & 732 & $\mathrm{C} 06$ & 243 & 1 to 180 & 25.63 & 4.62 \\
\hline BoTLP7 & Bol026844 & 741 & $\mathrm{C} 05$ & 246 & 1 to 184 & 25.46 & 4.83 \\
\hline BoTLP8 & Bol044836 & 402 & $\mathrm{C} 08$ & 133 & 1 to 72 & 14.66 & 8.29 \\
\hline BoTLP9 & Bol027694 & 978 & $\mathrm{C} 06$ & 325 & 1 to 185, trnsm 1 & 34.32 & 4.86 \\
\hline BoTLP10 & Bol039281 & 963 & $\mathrm{C} 02$ & 320 & 1 to 187 & 33.73 & 4.67 \\
\hline BoTLP11 & Bol026846 & 747 & $\mathrm{C} 05$ & 248 & 1 to 186 & 25.88 & 4.63 \\
\hline BoTLP12 & Bol016440 & 1287 & $\mathrm{C} 02$ & 428 & 1 to 190 & 45.33 & 4.95 \\
\hline
\end{tabular}

${ }^{\mathrm{z})}$ Brassica oleracea database (http://119.97.203.210/bolbase/blast/blast.html). 
genes are thaumatin-like genes.

For comparison of these BoTLPs with other published TLPs, an alignment search was carried out using a BLAST search of the NCBI database. The deduced amino acid sequences of 12 BoTLPs shared high homology, primarily with pathogenesis-related TLPs of $A$. thaliana and some other homologous species (Table 3). We again retrieved 41 pathogenesis-related TLP sequences of different plant species from NCBI and a phylogenetic tree was constructed with the deduced amino acid sequences of 12 TLPs of $B$. oleracea using the NJ method (Fig. 1). In the phylogenetic tree, 12 BoTLPs were divided into two main groups showing close relations with the PR TLP sequences of other plant species. Multiple alignment using PIR also revealed high similarity among the deduced amino acids of the TLPs of the two groups and the thaumatin protein of $T$. daniellii (Bennett) Benth (P02884), indicating their relatively conserved evolutionary relationship at the protein level (Fig. 2A and B). Thus, our results showed that the BoTLP genes showed high similarity with other PR TLPs and might play roles in defense activities against phytopathogens.

Table 3. Homology analysis of 12 thaumatin-like genes of Brassica oleracea $^{\text {z) }}$

\begin{tabular}{|c|c|c|c|c|c|}
\hline Protein & Top matched clones & $\begin{array}{l}\text { Top matched } \\
\text { protein }\end{array}$ & Identity & Top homologous species & References \\
\hline \multirow{2}{*}{ BoTLP1 } & NP568046 & PR TLP ${ }^{\mathrm{y})}$ & $86 \%$ & Arabidopsis thaliana & Mayer et al. (1999) \\
\hline & XP003540838 & TLP & $65 \%$ & Glycine $\max$ & Unpublished \\
\hline \multirow{2}{*}{ BoTLP2 } & NP173365 & PR TLP & $72 \%$ & A. thaliana & Theologis et al. (2000) \\
\hline & AEV57470 & TLP1 & $70 \%$ & Prunus persica & Sherif et al. (2012) \\
\hline \multirow[t]{2}{*}{ BoTLP3 } & AED93335 & PR TLP & $71 \%$ & A. thaliana & Tabata et al. (2000) \\
\hline & ХР004309088 & TLP1 & $71 \%$ & Fragaria vesca subsp. vesca & Unpublished \\
\hline \multirow{2}{*}{ BoTLP4 } & ABV89611 & PR TLP & $99 \%$ & B. rapa & Ahmed et al. (2013) \\
\hline & NP177503 & PR TLP & $96 \%$ & A. thaliana & Theologis et al. (2000) \\
\hline \multirow{2}{*}{ BoTLP5 } & NP001078513 & PR TLP & $93 \%$ & A. thaliana & Mayer et al. (1999) \\
\hline & ХP003540840 & TLP1 & $77 \%$ & G. $\max$ & Unpublished \\
\hline \multirow{2}{*}{ BoTLP6 } & NP177640 & TLP3 & $77 \%$ & A. thaliana & Theologis et al. (2000) \\
\hline & AEV57470 & TLP1 & $73 \%$ & P. persica & Sherif et al. (2012) \\
\hline \multirow{2}{*}{ BoTLP7 } & NP173365 & PR TLP & $71 \%$ & A. thaliana & Theologis et al. (2000) \\
\hline & BAD90814 & TLP & $66 \%$ & Cryptomeria japonica & Futamura et al. (2006) \\
\hline \multirow{2}{*}{ BoTLP8 } & NP180054 & PR TLP & $74 \%$ & A. thaliana & Lin et al. (1999) \\
\hline & XР003612186 & TLP & $64 \%$ & Medicago truncatula & Unpublished \\
\hline \multirow{2}{*}{ BoTLP9 } & ABV89616 & PR TLP & $88 \%$ & B. rapa & Ahmed et al. (2013) \\
\hline & NP177708 & PR TLP & $84 \%$ & A. thaliana & Theologis et al. (2000) \\
\hline \multirow{2}{*}{ BoTLP10 } & ABV89616 & PR TLP & $98 \%$ & B. rapa & Ahmed et al. (2013) \\
\hline & NP177708 & PR TLP & $85 \%$ & A. thaliana & Theologis et al. (2000) \\
\hline \multirow{2}{*}{ BoTLP11 } & NP173365 & PR TLP & $67 \%$ & A. thaliana & Theologis et al. (2000) \\
\hline & BAD90814 & TLP & $55 \%$ & C. japonica & Futamura et al. (2006) \\
\hline \multirow{2}{*}{ BoTLP12 } & NP197850 & PR TLP & $79 \%$ & A. thaliana & Unpublished \\
\hline & BAB11214 & TLP & $91 \%$ & A. thaliana & Sato et al. (1998) \\
\hline
\end{tabular}

\footnotetext{
${ }^{z)}$ Analyzed using BLAST from NCBI, http://www.ncbi.nlm.nih.gov/BLAST/.
}

${ }^{\text {y) }}$ PR TLP- Pathogenesis related thaumatin-like protein. 


\section{Organ-specific expression analysis}

Gene expression in different organ of cabbage was carried out by RT-PCR and varying expression pattern was observed (Fig. 3). Specifically, BoTLP1 and 10 showed expressions in all the organs tested except roots. BoTLP2 and 8 showed high level of expression only in leaves, while BoTLP3 showed expression in all organs except stem. BoTLP4, 7, 9 and 12 expressed only in the leaves and flower buds, while only BoTLP5 expressed in all organs tested. BoTLP6 and 11 expressed only in flower buds, indicating their probable role as allergen genes. Obviously, all genes described here showed higher level of expressions in leaves and flower buds compared to roots and stems. TLPs are now recognized as a new class of panallergens in food as well as in pollen (Breiteneder 2004). Moreover, the organs tested in this study share characteristics that make them particularly prone to pathogen attack. Adequate protection of these organs against pathogen attack is critical, and the production of an antifungal molecule could be part of a local defense strategy (Hamel and Bellemare 1995).

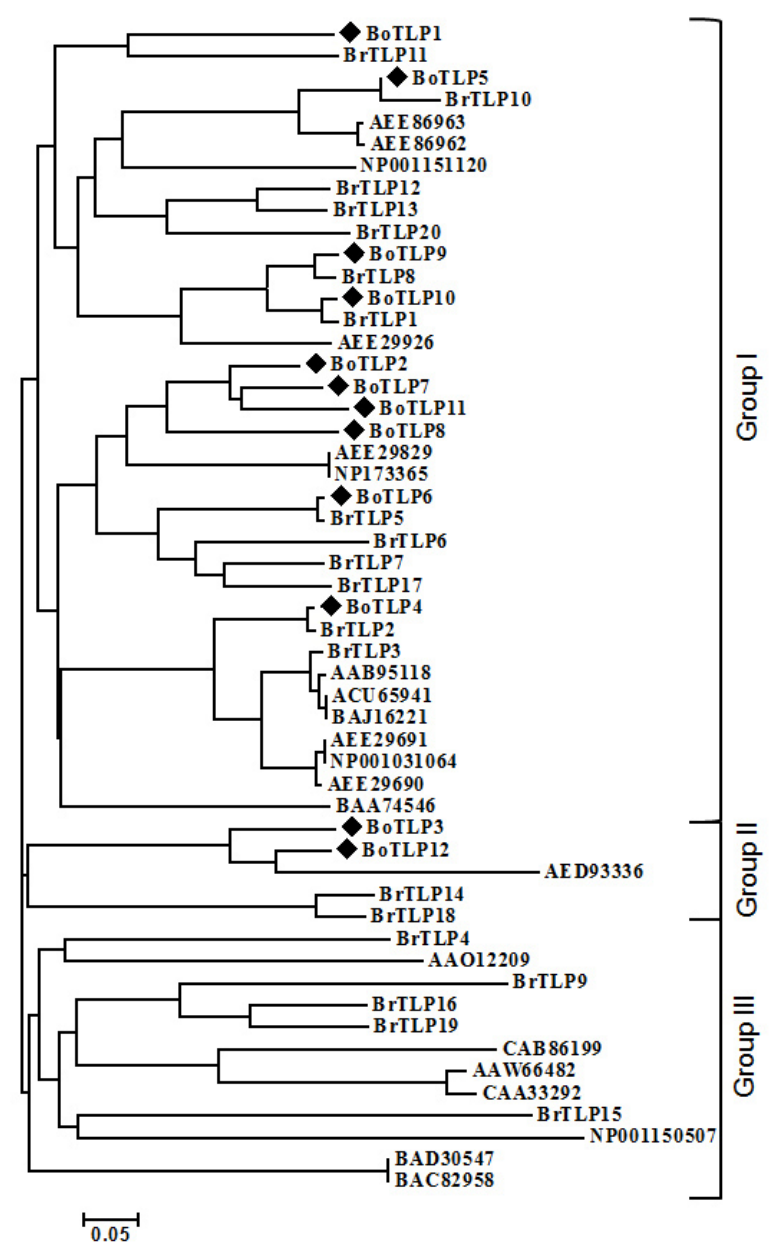

Fig. 1. Phylogenetic tree showing the relatedness of the deduced full-length amino acid sequences of 12 Brassica oleracea thaumatin-like proteins (BoTLPs) and 41 PR thaumatin-like proteins of other plant species. The phylogenetic tree was generated using MEGA5.05 program. The species names and the GenBank protein accessions numbers are indicated in brackets. Brassica oleracea (AAO12209), Brassica rapa (AAB95118), Brassica rapa subsp. chinensis (ACU65941 and BAJ16221), Oryza sativa Japonica Group (BAD30547 and BAC82958), Arabidopsis thaliana (AEE29691, AEE29690, NP001031064, AEE86963, AEE86962, AEE29829, NP173365, AED93336 and AEE29926), Solanum lycopersicum (CAB86199), Nicotiana tabacum (AAW66482, CAA33292 and BAA74546), Zea mays (NP001150507 and NP001151120) and BrTLP1 to 20 were taken from our previous study (Ahmed et al. 2013). The scale represents the frequency of amino acid substitution between sequences as determined by poisson evolutionary distance method. 


\section{Expression analysis after $\boldsymbol{P}$. carotovorum subsp. carotovorum infection}

Because EST analysis and previous studies indicated that thaumatin-like genes are biotic stress-related genes, we investigated the responses of the 12 BoTLPs identified in this study to infection by soft rot disease causing necrotroph bacteria, $P$. carotovorum subsp. carotovorum, which is a serious pathogen for Brassica. In the infected plants, expression of BoTLP5, BoTLP8 and BoTLP12 was differentially changed compared to mock-infected plants (Fig. 4A, B and C). BoTLP5 and BoTLP8 showed increased level of transcripts after $48 \mathrm{~h}$ of infection but decreased after $72 \mathrm{~h}$ (Fig. 4A and B). Interestingly, the expression of BoTLP5 and BoTLP8 in mock-infected plants was higher at the earlier periods of treatment than the later. Accordingly, the expression was 19-fold higher for BoTLP5 and 5-fold higher for BoTLP8, in the Pcc-infected plants than in mock-infected plants at $48 \mathrm{~h}$. On the other hand, transcript level of BoTLP12 was abruptly decreased just after infection and became almost inactive (Fig. 4C). It seems that only BoTLP5, 8 and 12 were induced among the BoTLPs after $P$. carotovorum subsp. carotovorum infection

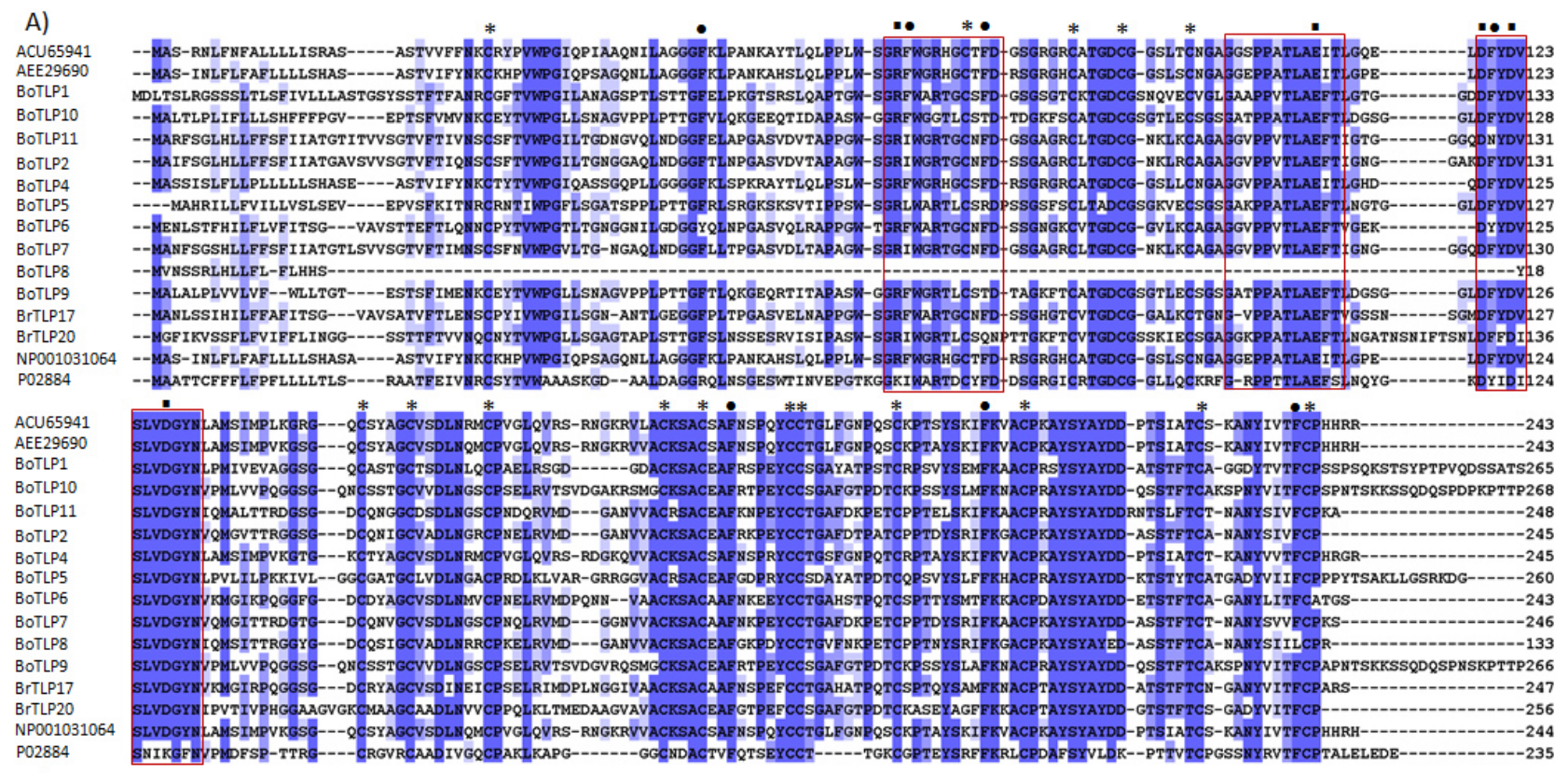

B)

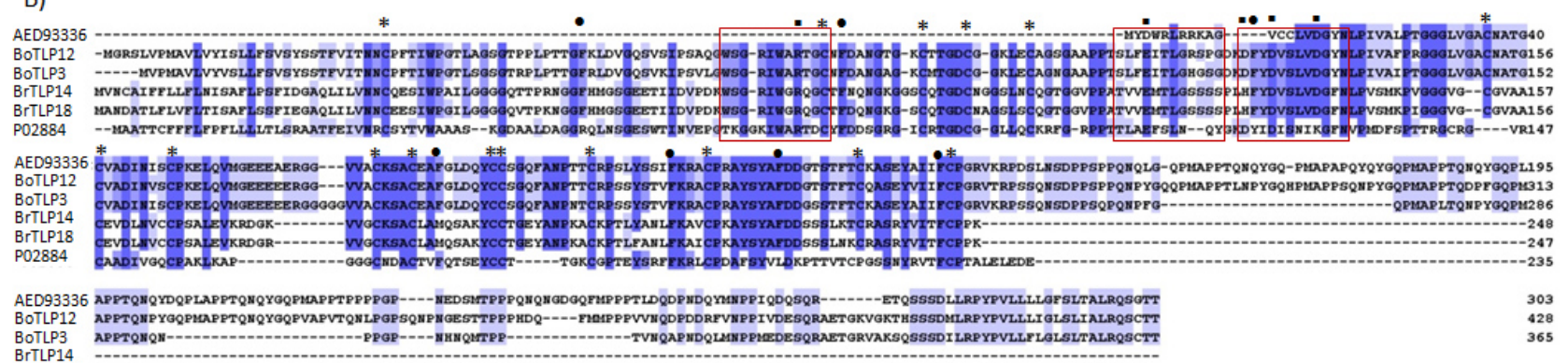

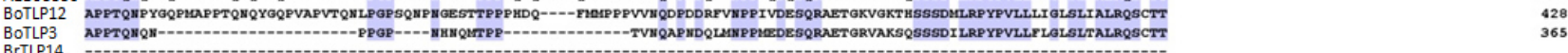

Fig. 2. Alignment of deduced amino acid sequences of (A) Group I thaumatin-like proteins; (B) Group II thaumatin-like proteins and sweet-tasting thaumatin protein of Thaumatococcus daniellii (Bennett) Benth. (P02884) in each group using PIR. Asterisk marks show all 16 conserved cysteine residues, square bullets indicate REDDD motif in the highly conserved region (rectangle) of the domain and circular bullets indicate FF hydrophobic motif described by Petre et al. (2011) in identical positions among the aligned proteins. Numbers on the right margin indicate the positions of amino acid residues. The identical amino acids are marked in dark background, and more than 50\% similarities in light. 


\begin{tabular}{|c|c|c|c|c|}
\hline & $\mathrm{R}$ & S & L & $\mathrm{Fb}$ \\
\hline BoTLP1 & & nongens & 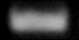 & \\
\hline BOTLP2 & & & 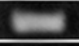 & \\
\hline BOTLP3 & 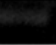 & & the & 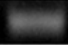 \\
\hline BOTLP4 & & & 2 & 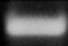 \\
\hline BOTLP5 & & D & 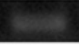 & 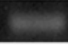 \\
\hline BoTLP6 & & & & 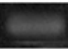 \\
\hline BoTLP7 & & & + & 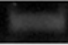 \\
\hline BOTLP8 & & & 달 & \\
\hline BOTLP9 & & & 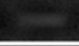 & 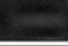 \\
\hline BoTLP10 & & $n$ & $x$ &  \\
\hline BoTLP11 & & & & 5 \\
\hline BoTLP12 & & & $x=$ & 20 \\
\hline BoActin & 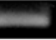 & 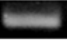 & 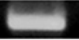 & 2 \\
\hline
\end{tabular}

Fig. 3. RT-PCR expression analysis of 12 BoTLP genes over different organs at Brassica oleracea plants. Lanes $1-4$, PCR products of roots (R), stems (S), leaves (L) and flower buds $(\mathrm{Fb})$

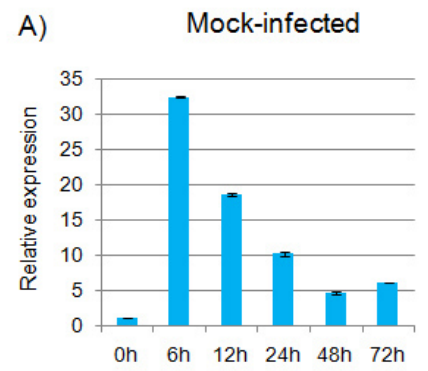

B)

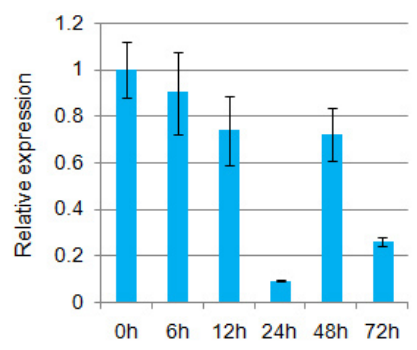

C)

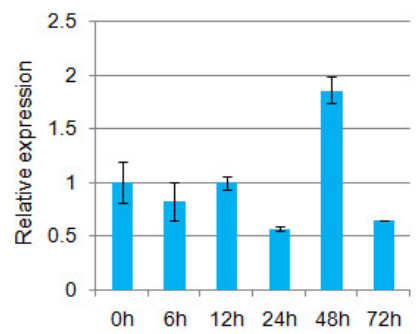

and possibly other genes might be responsive to other biotic stress agents. Thus, the results suggest that BoTLPs are PR TLPs and have probable involvement with biotic stress resistance.

Previous molecular studies of TLP expression, localization and activity support a role for TLPs in host defense during pathogen infection. TLP up-regulation has been described in many higher plants infected by pathogens such as bacteria, oomycetes and fungi (Liu et al. 2010; Mukherjee et al. 2010). It has also been suggested that the expression of PR-5 proteins (TLPs) contributes to resistance to different fungi (Vleeshouwers et al. 2000; Monot et al. 2002; Suo and Leung 2002). A PR5 thaumatin-like protein from A. thaliana ATLP3 expressed in bacteria showed considerable antifungal activity against pathogenic fungi such as $V$. alboatrum, $V$. dahlia, F. oxysporum and $A$.
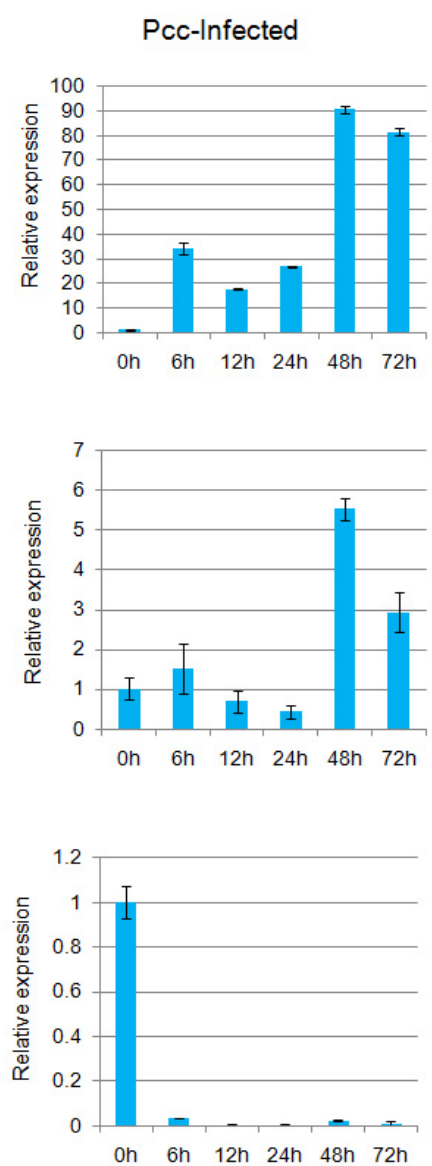

Fig. 4. Real-time quantitative PCR expression analysis of (A) BoTLP5, (B) BoTLP8 and (C) BoTLP12 genes in Brassica oleracea after infection with Pectobacterium carotovorum subsp. carotovorum (Pcc). The error bars represent the standard error of the means of three independent replicates. 
solani, as well as non-pathogenic fungi including T. reesei and C. albicans (Hu and Reddy 1997). Overexpression of cotton (Gossypium barbadense L.) thaumatin-like protein gene (GBTLP1) in tobacco exhibited considerable resistance against $V$. dahliae and $F$. oxysporum (Munis et al. 2010). Transgenic tobacco plants with thaumatin gene exhibited enhanced resistance with delayed disease symptoms against fungal diseases caused by Pythium aphanidermatum and Rhizoctonia solani (Rajam et al. 2007). A barley thaumatin-like protein $(H v-T L P 8)$ in transgenic oilseed rape (B. napus) exhibited enhanced resistance to the clubroot pathogen (Plasmodiophora brassicae) (Reiss et al. 2009). Taken together, the above discussion suggests the probable association of these genes with biotic stress resistance.

In this study BoTLP5, 8 and 12 responded positively after P. carotovorum subsp. carotovorum infection and for that it is mentionable that these genes could be considered as useful resources for biotic stress resistance. Thus, BoTLP5, 8 and 12 might be promising candidate for engineering Brassica resistant to biotic stresses. The remaining genes also might be useful for other biotic stresses resistance in Brassica, thus, investigations involving screening of these genes with other pathogens is recommended.

\section{ACKNOWLEDGEMENTS}

This work was supported by a grant from the NextGeneration BioGreen 21 Program (Plant Molecular Breeding Center No. PJ009085022012), Rural Development Administration, Republic of Korea.

\section{REFERENCES}

Ahmed NU, Park J, Jung H, Kang K, Lim Y, Hur Y and Nou I. 2013. Molecular Characterization of Thaumatin Family Genes Related to Stresses in Brassica rapa. Scientia Horticulturae. 152:26-34.

An lovar S and Dermastia M. 2003. The comparative analysis of osmotins and osmotin-like PR5 proteins. Plant Biol. 5: 116-124.

Bowles DJ. 1990. Defense-related proteins in higher plants.
Annu. Rev. Biochem. 59:873-907.

Breiteneder H. 2004. Thaumatin-like proteins-a new family of pollen and fruit allergens. Allergy. 59:479-481.

Chen WP, Chen PD, Liu DJ, Kynast R, Friebe B, Velazhahan R, Muthukrishnan S and Gill BS. 1999. Development of wheat scab symptoms is delayed in transgenic wheat plants that constitutively express a rice thaumatin-like protein gene. Theor. Appl. Genet. 99:755-760.

Collinge DB and Slusarenko AJ. 1987. Plant gene expression in response to pathogens. Plant Mol. Biol. 9:389-410.

Cortegano I, Civantos E, Aceituno E, del Moral A, Lopez E, Lombardero M, del Pozo V, and Lahoz C. 2004. Cloning and expression of a major allergen from Cupressus arizonica pollen, Cup a 3, a PR-5 protein expressed under polluted environment. Allergy. 59:485-490.

Dixon RA and Lamb CJ. 1990. Molecular communication in interactions between plants and microbial pathogens. Annu. Rev. Plant Physiol. Plant Mol. Biol. 41:339-367.

Fierens E, Rombouts S, Gebruers K, Goesaert H, Brijs K, Beaugrand J, Volckaert G, Van Campenhout S, Proost P, Courtin,CM and Delcour JA. 2007. TLX1, a novel type of xylanase inhibitor from wheat (Triticum aestivum) belonging to the thaumatin family. Biochem. J. 403:583-591.

Fitt B, Brun H, Barbetti M and Rimmer S. 2006. World-wide importance of phoma stem canker (Leptosphaeria maculans and L. biglobosa) on oilseed rape (Brassica napus). Eur. J. Plant Pathol. 114:3-15.

Fritz VA and Honma S. 1987. The effect of raised beds, population densities, and planting date on the incidence of bacterial in Chinese cabbage. J. Am. Soc. Hortic. Sci. 112:41-44.

Futamura N, Tani N, Tsumura Y, Nakajima N, Sakaguchi M and Shinohara K. 2006. Characterization of genes for novel thaumatin-like proteins in Cryptomeria japonica. Tree Physiol. 26:51-62.

Gaetan SA. 2005. Occurrence of Fusarium wilt on canola caused by Fusarium oxysporum F.sp. conglutinas in Argentina. Plant Dis. 89:432.

Garcia-Olmedo F, Molina A, Alamillo JM and RodriguezPalenzuela P. 1998. Plant defense peptides. Biopolymers 47:479-491.

Ghosh R and Chakrabarti C. 2008. Crystal structure analysis of NP24-I: a thaumatin-like protein. Planta 228:883-890.

Hamel F and Bellemare G. 1995. Characterization of a class I chitinase gene and of wound-inducible, root and flowerspecific chitinase expression in Brassica napus. Biochim. Biophys. Acta. 1263:212-220. 
Hejgaard J, Jacobsen S and Svendsen I. 1991. Two antifungal thaumatin-like proteins from barley grain. FEBS Lett. 291:127-131.

Hoffmann-Sommergruber K. 2002. Pathogenesis-related (PR)proteins identified as allergens. Biochem. Soc. Trans. 30:930-935.

Howlett BJ, Indurm A and Pedras MSC. 2001. Leptosphaeria maculans, the causal agent of blackleg disease of Brassica. Fungal Genet. Biol. 33:1-14.

$\mathrm{Hu}$ X and Reddy AS. 1997. Cloning and expression of a PR5-like protein from Arabidopsis: inhibition of fungal growth by bacterially expressed protein. Plant Mol. Biol. 34:949-959.

Iyengar RB, Smits P, Van der Ouderaa F, Van der Wel H, Van Brouwershaven J, Ravestein P, Richters G and Van Wassenaar PD. 1979. The complete amino-acid sequence of the sweet protein thaumatin. I. Eur. J. Biochem. 96:193-204.

Kitajima S and Sato F. 1999. Plant pathogenesis-related proteins: molecular mechanisms of gene expression and protein function. J. Biochem. 125:1-8.

Koiwa H, Kato H, Nakatsu T, Oda J, Yamada Y and Sato F. 1999. Crystal structure of tobacco PR-5d protein at $1,8 \AA$ resolution reveals a conserved acidic cleft structure in antifungal thaumatin-like proteins. J. Mol. Biol. 286: 1137-1145.

Li SD. 1995. Progress in disease resistant breed of main vegetables. Science Press, Beijing, pp.96-100.

Lin X, Kaul S, Rounsley S, Shea TP, Benito MI and Town CD et al. 1999. Sequence and analysis of chromosome 2 of the plant Arabidopsis thaliana. Nature. 402:761-8.

Liu D, Raghothama KG, Hasegawa PM and Bressan RA. 1994. Osmotin overexpression in potato delays development of disease symptoms. Proc. Natl. Acad. Sci. USA. 91:1888-1892.

Liu JJ, Sturrock R and Ekramoddoullah AKM. 2010. The superfamily of thaumatin-like proteins: its origin, evolution, and expression towards biological function. Plant Cell Rep. 29:419-436.

Mayer K, Schuller C, Wambutt R, Murphy G and Volckaert G. 1999. Sequence and analysis of chromosome 4 of the plant Arabidopsis thaliana. Nature. 402:769-777.

Midoro-Horiuti T, Goldblum RM, Kurosky A, Wood TG and Brooks EG. 2000. Variable expression of pathogenesisrelated protein allergen in mountain cedar (Juniperus ashei) pollen. J. Immunol. 164:2188-2192.

Monot C, Pajot E, Le Corre D and Silue D. 2002. Induction of systemic resistance in broccoli (Brassica oleracea var. botrytis) against downy mildew (Peronospora parasitica) by avirulent isolates. Biol. Control. 24:75-81.

Mukherjee AK, Carp MJ, Zuchman R, Ziv T, Horwitz BA and Gepstein S. 2010. Proteomics of the response of Arabidopsis thaliana to infection with Alternaria brassicicola. J. Proteomics. 73:709-720.

Munis M, Hussain F, Tu L, Deng F, Tan J, Xu L, Xu S, Long L and Zhang X. 2010. A thaumatin-like protein gene involved in cotton fiber secondary cell wall development enhances resistance against Verticillium dahliae and other stresses in transgenic tobacco. Biochem. Biophys. Res. Comm. 393:38-44.

Narasimhan ML, Coca MA, Jin J, Yamauchi T, Ito Y, Kadowaki T, Kim KK, Pardo JM, Damsz B, Hasegawa PM, Yun DJ and Bressan RA. 2005. Osmotin is a homolog of mammalian adiponectin and controls apoptosis in yeast through a homolog of mammalian adiponectin receptor. Mol. Cell. 7:171-180.

Ospina-Giraldo MD, Mullins E and Kang S. 2003. Loss of function of the Fusarium oxysporum SNF1 gene reduces virulence on cabbage and Arabidopsis. Curr. Genet. 44:49-57.

Petre B, Major I, Rouhie N and Duplessis S. 2011. Genome-wide analysis of eukaryote thaumatin-like proteins (TLPs) with an emphasis on poplar. BMC Plant Biol. 11:33.

Rajam MV, Chandola N, Goud Singh D, Kashyap V, Choudhary ML and Sihachakr D. 2007. Thaumatin gene confers resistance to fungal pathogens as well as tolerance to abiotic stresses in transgenic tobacco plants. Biol. Plant 51:135-141.

Reiss E, Schubert J, Scholze P, Kramer R and Sonntag K. 2009. The barley thaumatin-like protein Hv-TLP8 enhances resistance of oilseed rape plants to Plasmodiophora brassicae. Plant Breed. 128:210-212.

Ryals JA, Neuenschwander UH, Willits MG, Molina A, Steiner HY and Hunt MD. 1996. Systemic acquired resistance. Plant Cell. 8:1809-1819.

Saitou N and Nei M. 1987. The neighbor-joining method: a new method for reconstructing phylogenetic trees. Mol. Biol. Evol. 4:406-425.

Sakamoto Y, Watnabe H, Nagai M, Nakade K, Takahashi M and Sato T. 2006. Lentinula edodes tlgl encodes a thaumatin-like protein that is involved in lentinan degradation and fruiting body senescence. Plant Physiol. 141:793-801. 
Sato S, Kaneko T, Kotani H, Nakamura Y, Asamizu E, MiyajimaN and Tabata S. 1998. Structural analysis of Arabidopsis thaliana chromosome 5. IV. Sequence features of the regions of 1,456,315 bp covered by nineteen hysically assigned P1 and TAC clones. DNA Res. 5(1):41-54.

Schimoler-O'Rourke R, Richardson M and Selitrennikoff CP. 2001. Zeamatin inhibits trypsin and a-amylase activities. Appl. Env. Microbiol. 67:2365-2366.

Selitrennikoff CP. 2001. Antifungal proteins. Appl. Env. Microbiol. 67:2883-2894.

Sherif S, Paliyath G and Jayasankar S. 2012. Molecular characterization of peach PR genes and their induction kinetics in response to bacterial infection and signaling molecules. Plant Cell Rep. 31(4):697-711.

Suo Y and Leung DWM. 2002. Accumulation of extracellular pathogenesis-related proteins in rose leaves following inoculation of in vitro shoots with Diplocarpon rosae. Sci. Hortic. 93:167-178.

Tabata S, Kaneko T, Nakamura Y, Kotani H and Kato T et al. 2000. Sequence and analysis of chromosome 5 of the plant Arabidopsis thaliana. Nature. 408(6814):823-826.

Tamura K, Dudley J, Nei M and Kumar S. 2007. MEGA4: Molecular evolutionary genetics analysis (MEGA) software version 4.0. Mol. Biol. Evol. 24:1596-1599.

Theologis A, Ecker JR, Palm CJ and Federspiel NA. 2000. Sequence and analysis of chromosome 1 of the plant Arabidopsis thaliana. Nature. 408:816-20.

Van Loon LC, Rep M and Pieterse CM. 2006. Significance of inducible defense-related proteins in infected plants. Annu. Rev. Phytopathol. 44:135-162.

Van Loon LC and Van Kammen A. 1970. Polyacrylamide disc electrophoresis of the soluble leaf proteins from Nicotiana tabacum var. 'Samsun' and 'Samsun NN' II.
Changes in protein constitution after infection with tobacco mosaic virus. Virology. 40:199-211.

Van Loon LC and Van Strien EA. 1999. The families of pathogenesis-related proteins, their activities, and comparative analysis of PR-1 type proteins. Physiol. Mol. Plant Pathol. 55:85-97.

Van Loon LC. 2001. The families of pathogenesis-related proteins. $6^{\text {th }}$ International Workshop on PR-proteins. May 20-24, Spa, Belgium, Book of abstracts, p.9.

Vandermarliere E, Lammens W, Schoepe J, Rombouts S, Fierens E, Gebruers K, Volckaert G, Rabijns A, Delcours JA, Strelkov SV and Courtin CM. 2010. Crystal structure of the noncompetitive xylanase inhibitor $T L X 1$, member of the small thaumatin-like protein family. Proteins. 78:2391-2394.

Velazhahan R, Datta SK and Muthukrishnan S. 1999. The PR-5 family: thaumatin-like proteins, in: Datta S. K., Muthukrishnan S. (Eds.), Pathogenesis-related proteins in plants. CRC Press, Boca Raton, FL, pp.107-129.

Vigers AJ, Roberts WK and Selitrennikoff CP. 1991. A new family of plant antifungal proteins. Mol. Plant Microbe. Interact. 4:315-23.

Vleeshouwers VGAA, Van Dooijeweert W, Govers F, Kamoun S and Colon LT. 2000. Does basal PR gene expression in Solanum species contribute to non-specific resistance to Phytophthora infestans? Physiol. Mol. Plant Pathol. 57:35-42.

Yun DJ, Bressan RA and Hasegawa PM. 1997. Plant antifungal proteins. Plant Breed. Rev. 14:39-88.

Zhu B, Chen THH and Li PH. 1996. Analysis of late-blight disease resistance and freezing tolerance in transgenic potato plants expressing sense and antisense genes for an osmotin-like protein. Planta. 198:70-77. 